\title{
An Overview on Co-Efficient of Localization \& Localization Curve and Their Application Opportunities in the Context of Bangladesh
}

\author{
Md. Sohel Rana ${ }^{1} \&$ Fahim Hossain ${ }^{2}$ \\ ${ }^{1,2}$ Graduate, Department of Urban \& Regional Planning, BUET, Dhaka-1000, Bangladesh
}

\begin{abstract}
The paper contains an analytical discussion on the two important regional planning tools namely, 'co-efficient of localization' and 'localization curve'. Application opportunities of these tools in the context of a developing country like Bangladesh have been identified and depicted in the paper along with exploring their contribution in easing analytical regional planning.

Key-words: Base Magnitude; Co-efficient of Localization; Decentralization; Economic Entities; Localization Curve; Spatial Distribution.
\end{abstract}

\section{INTRODUCTION}

Bangladesh, a potential developing nation had seen tremendous flourish in its industrial sector in last couple of decades [1]. However, this industrial development concentrated mostly in few capital cities of Bangladesh [2]. Therefore, these cities envisage constant inflow of people from rural parts of the country which brings degraded quality of life, expensive living and unsafe work environment in cities [3] as well as socioeconomic inequality both in urban and rural areas [4].

Now-a-days, decentralization of administration and income sources is being talked about in Bangladesh with a view to attaining balanced as well as sustained regional economic growth [5]. This decentralization of economic sectors might work positive towards the depressurization of rural-urban migration and thus improving urban living environment as anticipated from expert's corner. In addition, diversification of income sources would ensure maximum employment opportunities to the unsaturated labor forces in rural parts which could be seen as another important indicator to the balanced regional development.

Co-efficient of localization and localization curve would render quick information on the spatial distribution patterns of an economic entity within a geographic unit. Therefore, these two regional planning tools could provide valuable guidelines to the policy makers in formulating policies for effective decentralization or diversification of income entities.

Now, decentralization of income sectors should be done according to the supply of labors or other raw materials in order to ensure smooth operation and profit to that income sector. For instance, garments industries should be decentralized based on availability of laborers; banking sectors based on agglomeration of financial transactions. A drug factory should not be relocated in such a location where cost for labor would be too high. In this case, co-efficient of localization and localization curve could recommend the best feasible location for a factory or economic entity too.

However, there are several types of industries such as tannery industry, chemical industry etc. which are expected not to expand or scatter at all because of their pollution generating nature. Co-efficient of localization and localization curve could provide preliminary idea to the policy makers of a country in this regard whether and how to control these industry's location and expansion.

Now, how these two planning tools should be applied in a developing country like Bangladesh needs to be explored. From this perspective, the study is undertaken to draw a generalized overview on these two regional planning tools along with discussing their application opportunities in Bangladesh.

\section{OBJECTIVE OF THE STUDY}

- To provide an overview on co-efficient of localization and localization curve

- To explore application opportunities of these two tools in regional planning of a developing country like Bangladesh.

III. CO-EFFICIENT OF LOCALIZATION

Co-efficient of localization, a regional planning tool measures the concentration of a phenomenon of interest (e.g. a given industry like manufacturing) relative to that of base magnitude across regions. Isard (1960) [6] stated that this is a measure of relative regional concentration of a given industry compared to some total 
national magnitude such as population, land area, manufacturing employment, income etc. He also mentioned that it is essentially a comparison of the percentage distribution by region of employment in the given industry with the regional percentage distribution of the base magnitude, for example total national manufacturing employment.

Variables used to build the coefficient are employment in the given industry, population, land area, gross product or income [6].

The co-efficient is generally used to determine the spatial distribution of given industries across regions or to find out the localization pattern of an economic sector. Moreover, the co-efficient provides preliminary idea on the issue "what to do" in order to ensure uninterrupted operation of an economic entity. For instance, a labor consumptive type of factory is found having more localization tendency within a small region. The concerning authority, in that case should undertake policies and measures to localize the skilled man-power and field specific laborers as well to get that factory flourished.

In addition, co-efficient of localization classifies economic entities according to their qualities of dispersion or concentration. The value of the co-efficient varies between 0 and 1 . The co-efficient value of 0 indicates exactly the same distribution of the given industry as the base magnitude or even distribution of the given industry. In transposition, the value approaches to unity if the entire industry is localized or concentrated in one small region.

Based on the co-efficient of localization, all industries of a country can be divided into three categories of high, low and medium co-efficient thrive industries. Industries with a low co-efficient value can thrive in different regions and are thus dispersed. Industries having a high co-efficient of localization are concentrated in particular regions.

The localization and regional specialization indices indicate that industries become more localized as regions become more specialized. Conversely, industries become more dispersed as regions become despecialized [7]. Therefore, it can be concluded that regional specialization would be a complementary tool to policy-makers in case of guiding the localization patterns of industries.

\subsection{Equation}

The formula used to calculate the co-efficient of localization for a given type of industry or economic entity is given below:

$$
\text { C.O.L }=\left[\sum\left|\left(s_{i} / n_{i}-S / N\right)\right|\right] / 100
$$

Where,

C.O.L $=$ Co-efficient of Localization

$\mathrm{s}_{\mathrm{i}}=$ Number of employment in a given industry in the region $i$;

$n_{i}=$ Number of employment in that type of industry in the nation;

$S=$ Number of employment in all industries in the same region;

$\mathrm{N}=$ Total number of employment in all industries in the country.

\subsection{Derivation of Co-efficient of Localization}

The Co-efficient of Localization is derived adopting following steps:

i. Subtracting each of the region's percentage shares of total system employment from its percentage share of total manufacturing employment in the system i.e. $\left(s_{i} / n_{i}-S / N\right)$;

ii. Adding all positive (or all negative) differences i.e. [ $\left.\sum \mid\left(s_{i} / n_{i}-S / N\right)\right]$;

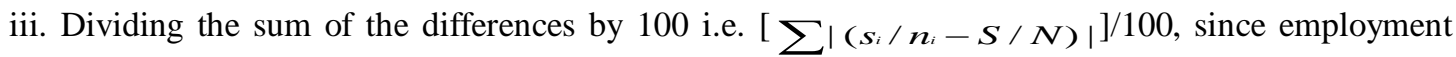
data are given in percentage share.

Derivation of the co-efficient can be elucidated from the Table-1 mentioned below.

Table-1: Derivation of Co-efficient of Localization

\begin{tabular}{|l|l|l|l|l|}
\hline \multirow{2}{*}{ Item } & Regions & B & C & D \\
\cline { 2 - 5 } & A & 30 & 35 & 15 \\
\hline Percent of employment of industry $i$ & 20 & 20 & 30 & 35 \\
\hline Percent of total U.S Manufacturing employment & 15 & +10 & +5 & -20 \\
\hline Difference (row 1-row 2) & +5 & 1.5 & 1.17 & 0.43 \\
\hline Location Quotient $^{1}$ (row 1/ row 2) & 1.33 & 1.5 \\
\hline
\end{tabular}

Source: Isard, (1960) [6]

\footnotetext{
${ }^{1}$ Location Quotient (LQ) is a related device for comparing a region's percentage share of a particular activity with its percentage share of some basic aggregate (Isard, 1960) [6].

LQ of region $\mathrm{A}=($ Percentage of regional employment in industry, A)/ (Percentage of national employment in industry, A)

For instance, a region with share of 20 percent of total regional employment in a given industry and 15 percent share of employment of total national industrial employment has LQ value of 1.33 .
} 
For the percentage share of employment of four regions shown in Table-1, the co-efficient of localization calculated is: $+20 / 100=0.2$

The value points to the nearly even distribution of the given industry compared to the employment throughout the country. This value of co-efficient indicates that the given type of industry doesn't need to be decentralized anymore as it is already diversified throughout the country. However, if the industry is characterized by emission generation nature, they should be centralized within a small region. Respective policy-makers should go for regional specialization such as localizing labors/input materials within that region to achieve the objective.

\subsection{Variants of Co-efficient of Localization}

If employment in another related industry is used as the base magnitude, the term co-efficient of localization is no longer used but 'co-efficient of geographic association'. This co-efficient compares the geographic distribution of a given industry to the geographic distribution of the base industry. If the population is used as the base magnitude, the co-efficient again signifies the relationship between the geographic distribution of a given industry with the geographic distribution of population [8]. When the value of this coefficient is zero, complete geographic association of the given industry exists; and when the value approaches to unity, geographic association tends to be disappeared.

In addition, some other related co-efficients are constructed for various purposes. These are 'coefficient of concentration of population', 'co-efficient of re-distribution' and 'co-efficient of deviation'.

\section{LOCALIZATION CURVE}

A tool superior in several ways to the co-efficient of localization and related co-efficients is the localization curve [6]. It is a device to assess the position of a region or to depict and rank regions by location quotient (LQ). It is a useful supplement of the co-efficient of localization but not the substitute.

Like-wise the co-efficient of localization, the curve is derived using variables - employment in the given industry, population, land area, gross product or income [6].

Localization curve depicts the spatial distribution pattern of given industry across regions compared to the base magnitude, like as co-efficient of localization. The curve is used to determine whether there is regional deviation of the particular industry from the regional pattern of industry in general. In addition, the curve measures the extent of regional concentration or deviation of an industry.

However, the use of a localization curve could be extended. More than one curve could be constructed to compare the distribution patterns of different industries at a given point of time or to compare the distribution of the same industry at different points of time [8].

\subsection{Derivation of Localization Curve}

Localization curve is derived from plotting a cumulative regional percentage figures for the given industry's employment on the vertical axis and the corresponding cumulative percentage figures for the national magnitude on the horizontal axis. Steps to construct the curve are mentioned below:

i. Ranking regions firstly in descending order on the basis of magnitude of location quotients. It should be done for all the selected industries.

ii. Plotting the regions by rank on cumulative percentage basis.

From the data set given in Table-1, it is seen that region B holds the highest LQ value among all. At the first step, therefore its percentage is plotted in Figure-1 (point 1 on curve ' $\alpha$ '). Region A is ranked second as it holds second highest LQ value. Region B's percentage therefore, is added to the corresponding percentage of region $\mathrm{A}$ to obtain the cumulative percentage figure for $\mathrm{A}$ region and then the cumulative percentage is plotted (point 2 on curve ' $\alpha$ '). Region $C$ ranks third in size of LQ for the industry $i$. Its percentages are added to the corresponding sums already obtained and then the resulting new sum is plotted (point 3 on curve ' $\alpha$ '). Finally the fourth ranked D region's percentage is added to yield 100 percent for both magnitudes and then plotted in Figure-1. Now, the plotted points are joined by straight line segments to construct the localization curve ' $\alpha$ '. 


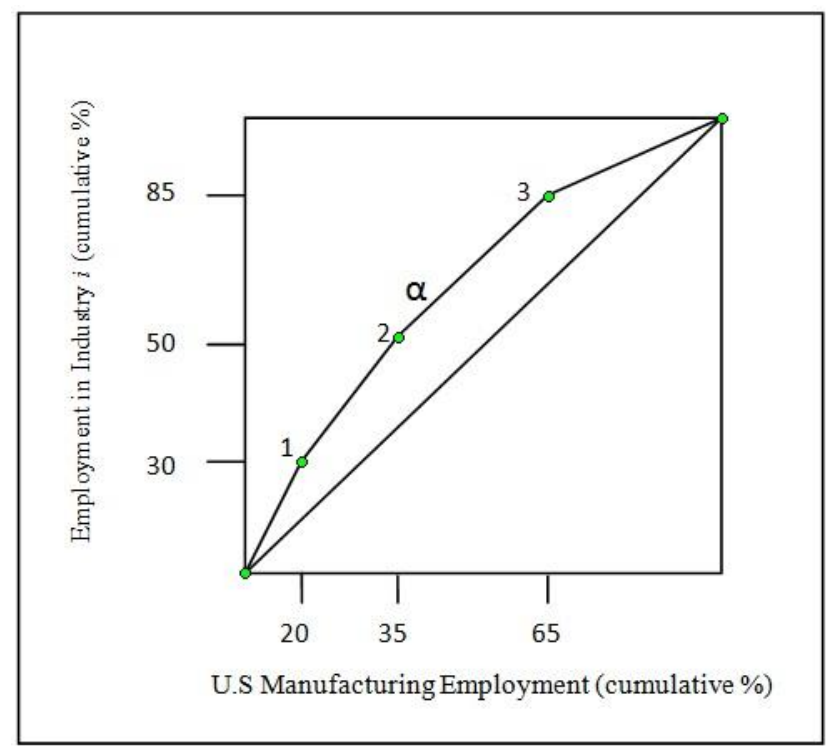

Figure-1: Localization Curve

The $45^{0}$ diagonal drawn from the origin indicates perfect equality of the industry's spatial distribution. If the regional distribution of given industry becomes exactly same as the base magnitude, the LQ will be unity and the curve will merge to the $45^{\circ}$ diagonal. The deviation of this curve above and to the left of $45^{\circ}$ diagonal reflects divergence in the distribution. The extent of this deviation is a measure of the regional concentration of the industry compared to the base magnitude. In this connection, co-efficient of localization can also be computed from the localization curve. Odongo (1979) [9] computed the co-efficient of localization from the localization curve as following:

Co-efficient of Localization (computed from Figure-2) $=($ Area of 'A' $) /($ Area of 'B')

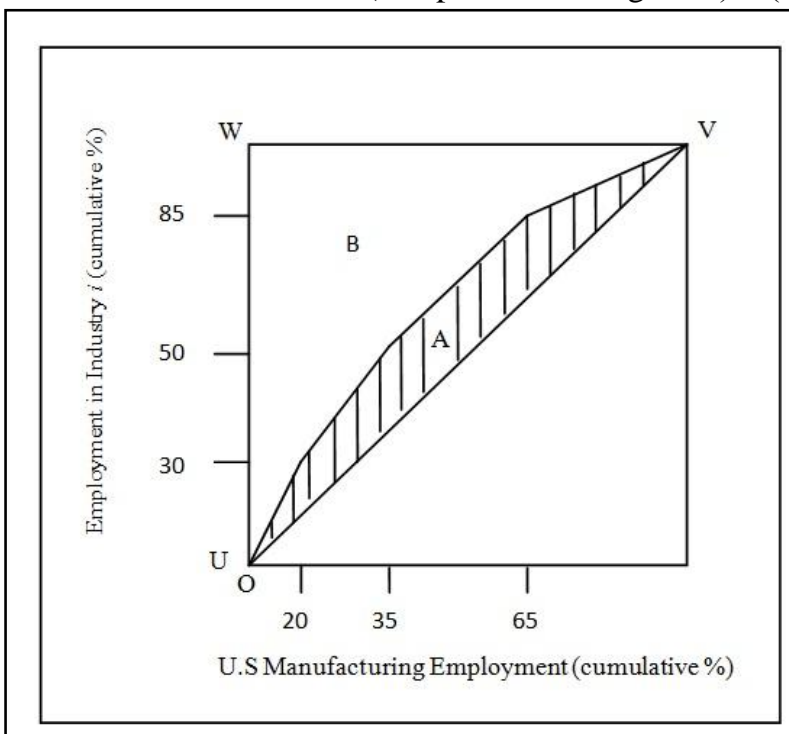

Area of 'A' $=$ Shaded

Area

Area of ' $\mathrm{B}$ '= Area

enclosed by UVW

Figure-2: Computation of Co-efficient of Localization from the Localization Curve

An analyst, for further analysis can derive more than one curve within the same figure for corresponding number of industries at a given point of time which will allow the analyst to compare and analysis the relative geographical pattern of those industries. Moreover, temporal geographic distribution patterns of a single type of industry can be construed if a number of curves are constructed for that type of industry at corresponding points of time.

\section{AdVANTAge OF LOCALIZATION CURVE OVER CO-EFFICIENT OF LOCALIZATION}

Application scopes of localization curve and co-efficient of localization are similar in nature. However, the curve involves several advantages over the co-efficient in case of construing an industry's distribution pattern. Localization curve renders pictorial demonstration on the distribution patterns of an economic entity at a glance. In addition, a number of localization curves for the same economic activity could be drawn for different 
points of time, which would provide information on the temporal variation in the distribution patterns of that economic activity. This aspect associated with localization curve can be seen as an advantage of the curve over the co-efficient of localization in the field of their application.

\section{LIMITATIONS OF CO-EFFICIENT OF LOCALIZATION AND LOCALIZATION CURVE}

The Co-efficient of localization and localization curve both involve some conceptual and technical shortcomings. These are discussed below:

i. Co-efficient of localization only reveals the existing state of distribution of industries in a particular country. It is incapable of explaining the reasons for particular form of concentration.

ii. The location factor is not always a sure guide to the degree of concentration of an industry because it is based on the number of industrial workers employed in each area.

iii. If the country is divided by counties rather than states, the co-efficient of localization of an industry compared to the total manufacturing workers becomes higher. Isard (1960) [6] stated that virtually an industry exhibits a high co-efficient of localization if the areal subdivision scheme is fine enough; that means, value of co-efficient decreases as larger subdivisions are considered. Thus, two different industries might have virtually the same co-efficient of localization if states were unit of subdivision but substantially different ones if counties were.

iv. The utility of the co-efficient and the curve very much depends on how broadly the base magnitude is defined. As Isard (1960) [6] pointed out, in a situation where a large proportion of country's total industry is concentrated in relatively few areas, a specific industry which happens to be also heavily concentrated in these same areas would most likely show a lower co-efficient if computation is based on total industrial employment.

\section{APPLICATION OPPORTUNITIES OF CO-EFFICIENT OF LOCALIZATION \& LOCALIZATION CURVE IN BANGLADESH}

i. In a developing country like Bangladesh characterized by huge unemployment problem, labor intensive industry or any economic activity's spatial development should be in proper way to provide sufficient employment opportunities to the unsaturated labors. Co-efficient of localization and localization curve can be used in this regard to determine whether spatial distributions of given type of industry have compatibility to the country-wise distribution of labor forces. Moreover, the extent of spontaneous decentralization of a type of industry over a period of time can be determined using the localization curve. For instance, if relative regional diversification of a type of industry increases over a period of time, it points to the spontaneous decentralization of that industry. Now, measuring the trend and extent of this spontaneous decentralization for a type of industry would be highly co-operative in regional development planning in Bangladesh.

ii. Spatial localization of industries should follow the spatial distribution patterns of corresponding rawmaterials. For example, sugarcane is raw-product to the molasses production. Molasses producing units within a district therefore, should be spatially distributed based upon the spatial variation in sugarcane production amount, to ensure sufficient market area and hence well and profitable functioning of each of the units. In transposition, these molasses producing units could also be distributed following the spatial distribution patterns of available labors across the region.

In this case, co-efficient of localization and localization curve can provide information regarding the basis of spatial localization of a type of industry. Let's say, spatial distribution pattern of type of industry is found more responsive to the availability of laborers than raw-materials. In other words, the industry is found having distributed across the region as same as the distribution pattern of its corresponding laborers but rawmaterials. In that case, policies for further decentralization or distribution of that type of industry should be formulated considering the available laborers as base magnitude but not the raw-materials. This issue associated with the two tools would guide towards attaining the effective decentralization of industries or economic entities.

iii. Several types of interdependent industries (e.g. garments and cotton factory) prefer to be located at close to each other to reduce the costs for transporting products and/or raw-materials. Garments sector is one of the most important sectors on which export economy of Bangladesh relies on [10]. Using the tool 'co-efficient of geographic association', a variant of co-efficient of localization, relative spatial distribution pattern of the cotton industries in respect to the geographic distribution pattern of garments industries can be measured and analyzed. This analysis would provide pursuit to make decisions for redistribution of the cotton industries across the region, if required.

\section{CONCLUSION}

Both the co-efficient of localization and localization curve discern and construe the spatial distribution pattern of a given type industry or economic entity. In a developing country like Bangladesh, income entities are expected to be diversified at local level to incorporate unused laborers in employment. These two tools could be 
used successfully in this regard to determine the extent of diversification for a given type of industry as well as to formulate policies for effective decentralization of industries or economic activities.

\section{REFERENCES}

[1] Rahman, A. (2013), "Time for Industry Audit — PM Must Intervene", Short article published in 'The Daily Star' newspaper, Bangladesh, June 11 .

[2] The World Bank (2007), "Bangladesh: Strategy for Sustained Growth- Chapter 5: Urban Development and Economic Growth in Bangladesh", Bangladesh Development Series, Paper No. 18, The World Bank Office, Dhaka, pp 104-105 [Retrieved from: http://siteresources.worldbank.org/SOUTHASIAEXT/Resources/Publications/448813-1185396961095/4030558http://siteresources.Worldbank.org/SOUTHASIAEXT/Resources

[3] Farhana K. M., Rahman S. A. \& Rahman M. (2012), "Factors of Migration in Urban Bangladesh: An Empirical Study of Poor Migrants in Rajshahi City", Bangladesh e-Journal of Sociology. Volume 9, Number 1. January 2012, pp 114-115. [Retrieved from: http://www.bangladeshsociology.org/Factors\%20of\%20Migration\%20in\%20Urban\%20Bangladesh\%20An\%20Empirical.pdf, Retrieved on: April 28, 2013]

[4] Shikdar, M. K. (2012), "Impact of Rural-Urban Migration on Urban Bangladesh", Social Science Research Network, December 21, p-11 [Retrieved from: http://papers.ssrn.com/sol3/papers.cfm?abstract_id=2217764, Retrieved on: April 28, 2013]

[5] The New Age (2013), "Experts Stress Decentralization to 'Save' Dhaka", Article published on June 2. [Retrieved from: http://newagebd.com/detail.php?date=2013-06-02\&nid=51297\#.UYHF0dggtkg, Retrieved on: June 6, 2013]

[6] Isard, W., (1960), Methods of Regional Analysis: an Introduction to Regional Science, The M.I.T Press, Massachusetts, Chapter 7, pp. 252-258.

[7] Kim, S. (1995), "Expansion of Markets and the Geographic Distribution of Economic Activities: The Trends in U.S. Regional Manufacturing Structure, 1860-1987”, The Quarterly Journal of Economics, Vol. 110, No. 4, p-894, November [Retrieved from: URL: http://www.ifpri.org/sites/default/files/publications/dsgdp13.pdf, Retrieved on: May 16, 2013]

[8] UN Asian and Pacific Development Institute (1980), A Glossary of Terms in Regional Planning and Development, Abhinav Publications, E-37 Hauz Khas, New Delhi-110016, pp 14 \& 55.

[9] Odongo, J.M.A.O. (1979), "The Spatial Distribution of Employees in Uganda (1963-1970)", Department of Rural Economy, Makerere University, Uganda, p-124.

[10] Tamanna, U. (2010), "Labor Unrest in Bangladesh RMG Sector: Does Active Labor Union Reduce the Risk of Labor Unrest in RMG Sector", Master's Dissertation (Master of Arts in Governance and Development), Institute of Governance Studies, BRAC University, Dhaka, Bangladesh, p-1, November $\quad$ [Retrieved http://dspace.bracu.ac.bd/bitstream/handle/10361/2087/Labor\%20Unrest \%20in\%20Bangladesh\%20RMG\%20Sector.pdf?sequence= 1, Retrieved on: June 7, 2013] 